\title{
An Assessment Methodology for the Fire Performance of School Bus Interior Components
}

\author{
EMIL BRAUN, JOHN H. KLOTE, SANFORD DAVIS, BARBARA C. LEVIN, \\ MAYA PAABO and RICHARD G. GANN
}

Center for Fire Research

National Institute of Standards and Technology

Gaithersburg, Maryland 20899, USA

A full-scale fire performance protocol for the evaluation of school bus seat assemblies was developed. This protocol is based on the results of full-scale testing of end-use seat assemblies and computer fire modeling of the ignition source and burning item(s) in a single compartment enclosure. Tenability criteria were applied to the results of the full-scale tests and computer fire model calculations. The results showed that temperature is a suitable criterion for this application. Toxicity of the decomposition products plays a secondary role in determining occupant survivability. Occupant tenability limits are exceeded for ignition sources over $300 \mathrm{~kW}$, independent of the type of seat assembly. Based on the full-scale test data, computer simulations were conducted to determine which tenability criteria were exceeded in the full-scale tests.

KEYWORDS: Bus; combustion products; fire performance; hazard; tenability; toxicity.

\section{INTRODUCTION}

Computer fire models provide fire researchers with a tool that can be used in developing standard test methods for fire performance evaluation of manufactured products. To date, computer fire models have been used to:

- determine relative comparison of material fire performance;

- re-create fire incidents; and

- predict smoke movement in an enclosure.

Computer simulations can also provide researchers with a unique opportunity to evaluate separately the impact of ignition source strength and a specific burning item on occupant response for various types of enclosures. In conjunction with full-scale testing, hazard analysis of a given fire scenario can reveal which fire hazard threat is the most important. From this 
information, a simplified test procedure can often be designed to assess the primary threat based on a few critical measurements. This type of analysis leads to an understanding of the relative importance of ignition source strength and product fire performance on the ultimate potential for occupant survivability.

We have developed a test procedure for the evaluation of school bus seat assemblies based on full-scale testing and computer fire model simulations [1]. Tenability criteria, which were applied to the results of both the fullscale tests and the computer fire model, were used to evaluate the potential for occupant survivability.

Full-scale tests were performed on each of six different seat assembly designs in a simulated school bus enclosure. For each test, three seat assemblies of a given design were placed in the enclosure. These seat assemblies were placed in three rows beginning in the rear corner of the enclosure. The seat assembly, located against the rear wall, was exposed to a $100 \mathrm{~kW}$ natural gas fire from a box burner having a surface area of $0.05 \mathrm{~m}^{2}$. Measurements were made of the:

- rate of heat release,

- mass loss rate,

- specific gas species ( $\left.\mathrm{CO}, \mathrm{CO}_{2}, \mathrm{O}_{2}, \mathrm{HCN}, \mathrm{HC} \ell\right)$ concentrations and yields, and

- upper and lower layer compartment temperatures.

Two possible reasons for the development of untenable conditions are the size of the ignition source and the fire performance of the material. Computer simulations were used to separate material performance from ignition source performance. Using the full-scale test measurements of heat, temperature and specific gaseous species yields as input data, computer simulations were conducted to determine which tenability criteria were exceeded in the full-scale tests. These results were used to compute minimum heat release rates that would cause comparable untenable conditions in a standard size room [3]. These results showed that a temperature criterion is sufficient to distinguish between the flammability of the seat assemblies that represent a hazard to school bus occupants when exposed to moderate ignition sources.

\section{TENABILTTY}

Tenability criteria are used to determine, in an idealized sense, when one can reasonably assume that escape from the fire environment becomes impossible. These criteria correspond to human response to a fire environment. Escape is defined as the ability to vacate an enclosure or to find a safe haven within the enclosure. These tenability criteria deal with human response limits to:

- temperature (convective heat transfer to the body);

- irradiance (radiant heat transfer to the body);

- smoke density (impairment of visibility); and

- smoke toxicity.

Tenability limits are time-integrated functions of the intensity of exposure. Therefore, no single set of limit values can be defined for incapacitation or lethality due to temperature, irradiance, and toxicity. It is also assumed that an occupant's ability to move about a smoke-filled space controls the exposure time for the other three parameters. For a detailed 
discussion of these tenability limits and the formulas used to calculate these limits, the reader is directed to the HAZARD I manuals [2].

The tenability limits used in this analysis are shown in table 1 . They are the limits used by the tenability evaluation program in HAZARD $I$. The analysis is based on a single compartment idealization of a school bus and, therefore, does not consider the impact of flashover on bus occupants. A fully developed room fire or flashover represents a dramatic increase in temperature, heat flux, smoke obscuration, and toxic gases. The tenability

\begin{tabular}{|c|c|c|c|}
\hline \multicolumn{4}{|c|}{ Table 1. Tenability Limits used in HAZARD } \\
\hline Cause & Symbo I in HAZRAD I & Incapacitation Level & Lethal Leve1 \\
\hline Temperature (HAZARD Beta test) & TEMP1 & $65^{\circ} \mathrm{C}$ & $100^{\circ} \mathrm{C}$ \\
\hline Temperature (FED due to convective heat) & TEMP2 & 1 & $M A^{C}$ \\
\hline Heat Flux (irradiance) & FLUX & $\mathrm{NV}^{\mathrm{d}}$ & $\mathrm{NA}$ \\
\hline $\begin{array}{l}\text { Toxic Gases (FED due to } \mathrm{CO}, \mathrm{CO}_{2} \text {, HCN, d } \\
\mathrm{O}_{2} \text { from HAZARD Beta Test) }\end{array}$ & FED1 & 0.5 & 1 \\
\hline $\begin{array}{l}\text { Texic Gases (FED-Purser's mode1 due to } \\
\left.\mathrm{CO}, \mathrm{CO}_{2}, \mathrm{HCN}, \& \mathrm{O}_{2}\right)\end{array}$ & FED2 & 1 & NA \\
\hline Toxic Gases (Concentration-Time product) & $\mathrm{CT}$ & $450 \mathrm{~g}-\mathrm{min} / \mathrm{m}^{3}$ & $900 \mathrm{~g}-\mathrm{min} / \mathrm{m}^{3}$ \\
\hline $\begin{array}{l}\text { Default tenability limits from referenc } \\
\text { bractional Effective Dose. } \\
\text { c Not Applicable. } \\
\text { do single value because incapacitation } \\
\text { exposure history. }\end{array}$ & tue to heat flux de & ids on & \\
\hline
\end{tabular}

limits listed in table 1 occur well before the development of a fully involved room fire.

\section{MATERIALS}

Six different seat assembly designs were selected to represent a wide range of expected fire performance. The primary materials for each assembly design were a single padding and a single cover fabric. Each assembly consisted of back and botton cushions attached to a tubular steel frame. The seat back unit contained a $6 \mathrm{~mm}$ plywood insert and the seat cushion unit contained a $13 \mathrm{~mm}$ plywood insert. A summary of the materials and their physical measurements is given in Table 2. The standard foam for this study,

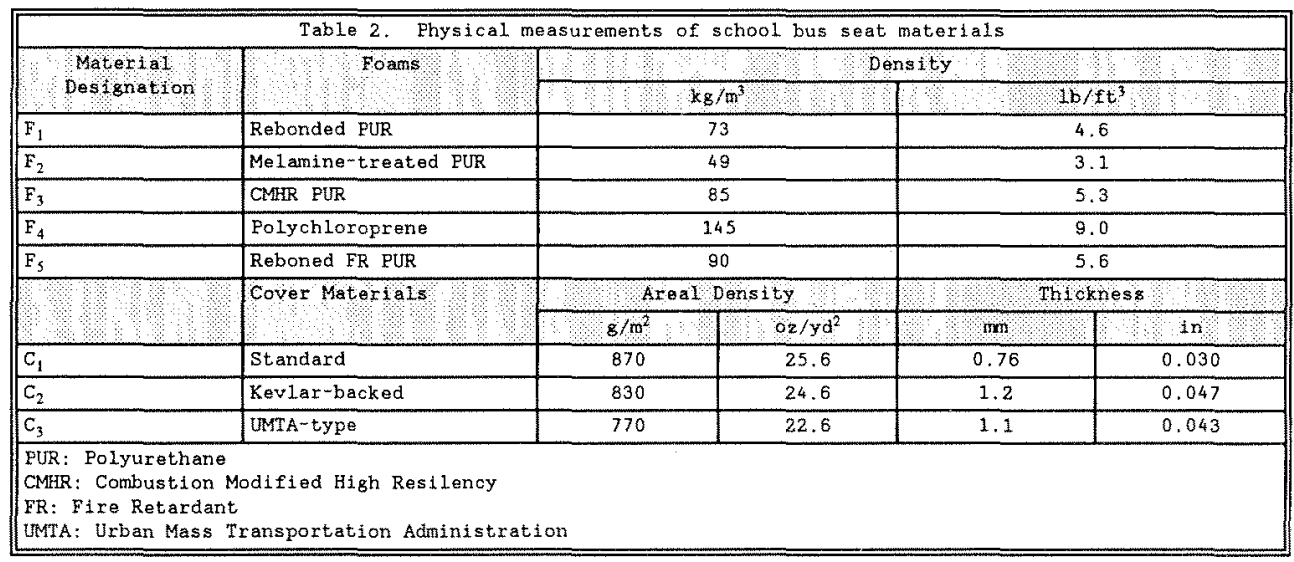


$F_{1}$, is a rebonded polyurethane typical of current production by the bus manufacturer; expanded polystyrene beads were distributed throughout the foam matrix. Foam $F_{2}$ is a melamine-treated polyurethane. $F_{3}$ is a combustionmodified high-resiliency (CMHR) polyurethane foam. Foam $F_{4}$ is a low smoke polychloroprene and $F_{5}$ is a rebonded flame retardant-treated polyurethane foam. Gover material $C_{1}$ is typical of current production. It is a calendered vinyl bonded to a knitted polyester scrim. Cover material $C_{2}$ is a calendered vinyl bonded to a loosely woven polyester scrim to which was applied a nonwoven Kevlar backing. $C_{3}$ cover material is a calendered vinyl bonded to a double-knit polyester fabric. This cover material was certified by the manufacturer to meet the Urban Mass Transportation Administration (UMTA) guidelines [4].

\section{FULL-SCALE TEST}

In each of six tests, three seat rows (each with one seat assembly) were installed in one corner of a simulated school bus compartment as they would be in a real school bus. In this way, flame spread across a seat assembly and from seat assembly to seat assembly could be observed. Ignition was accomplished by a box burner located adjacent to the aisle edge of the rearmost seat assembly. The burner, fueled by natural gas, was adjusted to produce a $100 \mathrm{~kW}$ flame. This heat release rate approximates a gasoline spill of about the same surface area; it did not contribute so much heat into the compartment as to mask the performance of the seat assemblies.

The experimental arrangement consisted of a single compartment measuring $2.44 \mathrm{~m}$ wide by $2.13 \mathrm{~m}$ high by $8.23 \mathrm{~m}$ long, lined with noncombustible materials. A doorway measuring $1.02 \mathrm{~m}$ wide by $1.83 \mathrm{~m}$ high provided the sole ventilation path into and out of the compartment. These dimensions approximate a full size school bus as determined by field inspection of actual school buses. (Note: Thermal properties of construction materials are found in reference [5].) For details on instrumentation type and placement, see reference [1].

\section{FIRE MODELING}

Computer modeling was used to evaluate the development of hazardous conditions in a compartment. HAZARD $I$ is a sequence of procedures implemented in computer software to calculate the development of hazardous conditions over time, to calculate the time needed by building occupants to escape under those conditions, and to estimate the resulting loss of life based on assumed occupant behavior and tenability criteria. These calculations are performed for a specified enclosure and set of fire scenarios of concern.

HAZARD I is used in this work to assess the changes in a compartment environment caused by the presence of an ignition source or burning item of known energy release rate and the resulting tenability times of temperature, ixradiance, and toxicity. This information is used to demonstrate the relative importance of the three tenability criteria (i.e., temperature, irradiance, and toxicity) in evaluating hazardous conditions in a single compartment enclosure. Also, the tenability portion of HAZARD I is used to determine times to incapacitation and lethality for temperature, irradiance, and toxicity in the full-scale tests of the six seat assemblies. As will be seen, this tool is used to determine an upper limit for the ignition source 
intensity, such that the ignition source does not become the limiting factor affecting time to escape from a burning school bus.

\section{FULL-SCALE TESTS RESULTS}

These tests determined when hazardous conditions would develop in the compartment and the likelihood of flame propagation from seat-to-seat. However, it should be recognized that the actual numerical values obtained in these full-scale tests depend on the size and shape of the compartment and the doorway opening. For the same size door opening and fire size, smaller compartments could be expected to achieve untenable conditions sooner. Also, it should be noted that unlike a "real bus fire," air flow in and out of the compartment was restricted to the doorway opening. Broken windows could dramatically alter the development of untenable conditions in a bus.

A full-scale test was conducted with only the ignition burner in the compartment. The burner was placed in the same location it would occupy when seat assemblies were in position on the load platform. This test was performed to determine the threat to occupants represented by the burner in the bus simulation independent of the seat assemblies under test. The threat posed by the ignition burner was assessed by the depth and temperature of the upper layer of hot gases in the compartment, the gas concentrations of $\mathrm{CO}$, $\mathrm{CO}_{2}$, and $\mathrm{O}_{2}$ and the irradiance level received by two targets. One target was located on the wall opposite the ignition burner, the second at the mid-point of the floor of the bus simulation. The irradiance level at the latter location was calculated from measurements of the upper gas temperature and location of the interface.

The average heat release rate during steady-state burning of the ignition burner alone was $100 \pm 9 \mathrm{~kW}$. The data for various burner parameters are incorporated into the tables describing seat assembly test results. For both burner and seat assembly tests, a separation was observed between the upper hot gases and lower cool gases. This separation is consistent with the basic assumption of zone models and encourages their use in assessing fire growth in a compartment.

Then followed a series of six fire tests using six foam and fabric combinations of cushion material and cover fabric listed in table 2. Material combination $F_{1} / C_{1}$ not only ignited and burned the entire width of the first seat assembly but also propagated the flames from seat-to-seat. Four minutes after ignition of the burner, all three seat assemblies for material combination $F_{1} / C_{1}$ were actively burning. The initial weight of these seats was $36.0 \mathrm{~kg}$. Approximately $99 \%$ of the initial mass was consumed.

Material combination $F_{2} / C_{3}$ exhibited flame spread along the entire exposed seat assembly and ignition, but limited flame spread, on the back of the second seat assembly. Approximately $15 \%$ of the inital $29.6 \mathrm{~kg}$ was consumed.

During four seat assembly tests $\left(F_{1} / C_{2}(34.6 \mathrm{~kg}), F_{3} / C_{3}(37.7 \mathrm{~kg}), F_{4} / C_{3}\right.$ $(49.1 \mathrm{~kg})$, and $F_{5} / C_{3}(51.8 \mathrm{~kg})$, for which behavior was similar, burning and flame spread were limited to a portion (less than 50 percent of the surface area) of the seat assembly first exposed to the ignition burner. Seat assemblies $\mathrm{F}_{4} / \mathrm{C}_{3}$ and $\mathrm{F}_{5} / \mathrm{C}_{3}$ lost only $1 \%$ of their initial mass. Seat assembly $\mathrm{F}_{1} / \mathrm{C}_{2}$ lost $2 \%$ of its initial mass. There was some thermal degradation observed on the back of the second seat but flames did not spread along the length of 
the first seat assembly nor from seat-to-seat. The seat back forward of the ignition seat assembly for test $F_{3} / C_{3}$ also thermally degraded without igniting and spreading the fire from seat-to-seat. This seat assembly 1 ost $10 \%$ of its initial mass.

Table 3 summarizes the heat release rate, HRR, data in terms of the peak HRR and the $60 \mathrm{~s}$ average about the peak HRR. The time to peak HRR is also tabulated. These values were calculated from measurements of the exhaust gases exiting the simulated bus compartment. The highest peak and average HRR values were obtained with the $F_{1} / C_{1}$ seat assembly, $3045 \mathrm{~kW}$ and $2780 \mathrm{~kW}$, respectively. This was followed by seat assemblies $F_{2} / C_{3}$, with a peak $H R R$ of

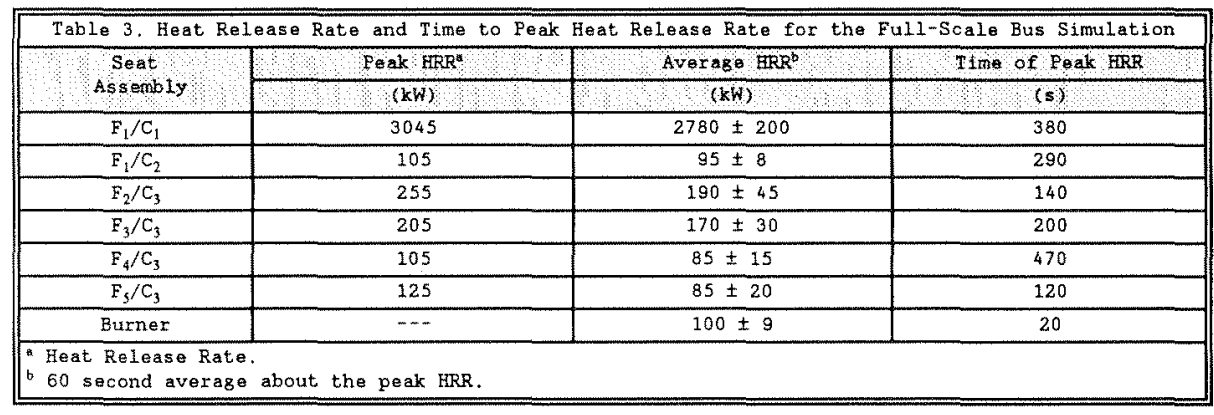

$255 \mathrm{~kW}$ and an average HRR of $190 \mathrm{~kW}$, and $\mathrm{F}_{3} / \mathrm{C}_{3}$, with a peak HRR of $205 \mathrm{~kW}$ and an average $\mathrm{HRR}$ of $170 \mathrm{~kW}$ - an order of magnitude below seat assembly $\mathrm{F}_{1} / \mathrm{C}_{1}$. Three seat assemblies, $F_{1} / C_{2}, F_{4} / C_{3}$, and $F_{5} / C_{3}$, had $H R R$ values, peak and average, which were 50 percent below the values obtained from seat assemblies $\mathrm{F}_{2} / \mathrm{C}_{3}$ and $\mathrm{F}_{3} / \mathrm{C}_{3}$.

Tables 4 summarize the results of these tests by tabulating the location of the interface in the center of the compartment at the time of maximum upper compartment temperature as well as the temperature below the interface. At maximum upper compartment temperature, the interface height was approximately $1.2 \mathrm{~m}$ except for test $\mathrm{F}_{1} / \mathrm{C}_{1}$. It was during test $\mathrm{F}_{1} / \mathrm{C}_{1}$ that the compartment achieved flashover conditions (i.e., upper compartment temperature above $600^{\circ} \mathrm{C}$ ). These results show that at the maximum upper compartment temperature, only seat assembly $F_{1} / C_{1}$ had an interface location below $1 \mathrm{~m}$ and a lower compartment temperature above the upper compartment temperature of the $100 \mathrm{~kW}$ gas burner test. For the other seat assemblies, the location of the interface at this time was approximately the same as observed with only the gas burner.

\begin{tabular}{|c|c|c|c|c|}
\hline Table 4. Bei & ht of the Interface & at the Time of Maximum & Upper Layer Temperatura & in Simulated Bus \\
\hline \multirow[t]{3}{*}{ Seat Assenbly } & \multicolumn{4}{|c|}{ at Maxinum Upper Layer Temperature } \\
\hline & Hetght & Time & Upper Layer & Lover Layer \\
\hline & ते & $(s)$ & $\left(\mathrm{C}^{\circ}\right.$ & $t^{\circ} \mathrm{Cl}$ \\
\hline $\mathrm{F}_{1} / \mathrm{C}_{1}$ & 0.22 & 337 & 668 & 133 \\
\hline$F_{1} / C_{2}$ & 1,20 & 267 & 136 & 36 \\
\hline $\mathrm{F}_{2} / \mathrm{C}_{3}$ & 1,19 & 107 & 183 & 37 \\
\hline $\mathrm{F}_{3} / \mathrm{C}_{3}$ & 1.18 & 147 & 173 & 37 \\
\hline$F_{4} / C_{3}$ & 1.20 & 467 & 141 & 37 \\
\hline $\mathrm{F}_{5} / \mathrm{C}_{3}$ & 1.22 & 77 & 138 & 30 \\
\hline Burner & 1.18 & -- & 125 & 33 \\
\hline
\end{tabular}


Applying the tenability criteria used in HAZARD I to the full-scale test data in the rear of the compartment shows that three of the seat assemblies generated an enclosure environment expected to result in incapacitation or death to occupants within a two- to three-minute time period (Table 5). Complete evacuation of an enclosure under these test conditions would have to be accomplished within this time period to ensure that occupants not be exposed to lethal conditions. With the ignition source used in these simulations (100 kW), the other three seat assemblies did not develop a debilitating atmosphere within the enclosure during the entire duration of the test. A larger ignition source would itself have resulted in the development of untenable conditions in the enclosure even without any involvement of seat assemblies.

\begin{tabular}{|c|c|c|c|c|c|c|}
\hline \multirow[t]{2}{*}{ Seat Assant/y } & \multicolumn{3}{|c|}{ Time to Incapocstat fon $(s)$} & \multicolumn{3}{|c|}{ Tive to Death $(s)$} \\
\hline & Temperatura & Irfadiance & FED & Tenperature & Irradlance & FED \\
\hline$F_{1} / C_{1}$ & 167 & 237 & 367 & 167 & -- & 427 \\
\hline$F_{1} / C_{2}$ &.$---b$ & $\overline{-\infty}$ & $\ldots$ & -- & -- & $-\infty$ \\
\hline $\mathrm{F}_{2} / \mathrm{C}_{3}$ & 117 & $\cdots$ & -- & 117 & $\cdots \cdots$ & 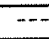 \\
\hline $\mathrm{F}_{3} / \mathrm{C}_{3}$ & 147 & $\cdots$ & --- & 147 & $-\cdots$ & --- \\
\hline$F_{4} / C_{3}$ & $\cdots$ & $m-$ & -- & $-\cdots$ & -- & $m-$ \\
\hline$F_{5} / C_{3}$ & $-\infty$ & $\cdots$ & -- & $-\cdots$ & $-\cdots$ & -- \\
\hline
\end{tabular}

\section{FIRE MODELING RESULTS}

Since various ignition sources maybe encountered in the day-to-day operation of a school bus, it is necessary to determine the impact of the strength of the ignition source on the habitability and egress potential from the bus interior, independent of the presence of any interior furnishings. This will provide a basis for the selection of seat materials based on acceptable fire performance. Ideally, the available time for escape associated with a given ignition source strength (i.e., rate of heat release) should not be significantly reduced by material performance when exposed to such an ignition source. The determination of acceptable egress times for a school bus enclosure, which is beyond the scope of this paper, must include the physical state of the occupants, the physical state of the school bus (e.g., upright or overturned), the availability and accessibility of exit paths, and the availability of external assistance (police, rescue, and fire services personnel).

A series of computer simulations were performed with HAZARD I based on the school bus configuration employed in the full-scale experiments. The strength (i.e., heat release rate) of the heat source was varied from $100 \mathrm{~kW}$ (as in the experiments) to $1000 \mathrm{~kW}$. For these simulations, it was assumed that approximately 20 seconds is required to achieve a full-power steady-state heat release rate. In the actual burner experiments, time to steady-state heat release ranged from 30 to 90 seconds, mostly due to operator adjustments to the flow control valve.

Figure 1 shows the upper and lower compartment temperatures resulting from simulated heat release rates of $100 \mathrm{~kW}, 250 \mathrm{~kW}, 500 \mathrm{~kW}$, and $1000 \mathrm{~kW}$. If compartment flashover is defined as an upper layer temperature of approximateIy $600^{\circ} \mathrm{C}[6]$, then a heat release rate of about $1000 \mathrm{~kW}$ will cause compartment 
flashover in approximately 200 seconds. The lower compartment temperature at this time is calculated to be $110^{\circ} \mathrm{C}$, which is untenable. While the upper layer of the compartment developed untenable conditions in every computer simulation (for both incapacitation and lethality), the lower layer first requires a $250 \mathrm{~kW}$ ignition source to became incapacitating and a $1000 \mathrm{~kW}$ ignition source to become lethal. Because of the anticipated human response to the elevated temperatures in the upper layer (i.e., individuals will drop to the floor when the upper layer temperature exceeds $50^{\circ} \mathrm{C}$ ), tenability is judged by conditions in the lower layer. For the given geometric conditions and doorway opening, the model in no case predicted the height of the lower layer to be less than $1 \mathrm{~m}$ from the floor. This provides an escape path of relatively clean air for occupants leaving an upright burning school bus with an open door. If the ignition source is greater than $500 \mathrm{~kW}$, the ignition source controls the rate of fire growth and the development of untenable conditions. Therefore, the type of seat assembly installed in the school bus does not markedly affect the time to develop an incapacitating or lethal environment.

Having developed a criterion for the selection of an upper limit on ignition source strength, computer fire modeling can also be used to define the measurement needs of a standard test method. Using the standard size room configuration described above, HAZARD I was used to determine the minimum fire size that reaches specific tenability limits. Since the full-scale tests exhibited two distinct fire durations of 300 seconds and 1000 seconds, two generalized heat release rate curves were used for this portion of the analysis, figure 2 .

The steady heat release rate listed in each line of Table 6 is the smallest value (within $1 \mathrm{~kW}$ ) calculated by HAZARD I that will indicate that a specific tenability limit has been reached (see table 1). For lethality conditions,

\begin{tabular}{|c|c|c|c|c|}
\hline & & & & \\
\hline 300 & & 49 & FLUX & - \\
\hline 300 & & 347 & TEMP1 & - \\
\hline 300 & & 568 & TEMP2 & - \\
\hline 300 & & 568 & $=$ & TEMP1 \\
\hline 1000 & & 11 & FLUX & $\overline{-}$ \\
\hline 1000 & & 323 & TEMP1 & - \\
\hline 1000 & & 548 & - & TEMP1 \\
\hline 1000 & & 560 & TEMP2 & - \\
\hline
\end{tabular}

the TEMP1 criterion was reached at $568 \mathrm{~kW}$ for a 300 second duration fire and at $548 \mathrm{~kW}$ for a 1000 second duration fire. For incapacitation, it was found that the FLUX criterion was activated at $49 \mathrm{~kW}$ for a 300 second duration fire and at $11 \mathrm{~kW}$ for a 1000 second duration fire. The TEMP1 criterion was reached at $347 \mathrm{~kW}$ and $323 \mathrm{~kW}$ for a 300 second and 1000 second duration fire, respectively. TEMP2 criterion was activated at $568 \mathrm{~kW}$ and $560 \mathrm{~kW}$ for comparable duration fires. Since it was assumed that school bus occupants would normally be clothed and the tenability limit due to heat flux in. TENAB is for bare skin, the FLUX criterion is not appropriate for the proposed test protocol. 
The impact of toxicity on school bus occupants was determined by calculating an $\mathrm{LC}_{50}$ of the gases in the standard size room and comparing this to toxicity data from the animal tests. In order for this to be a rigorous comparison, it was assumed that the combustion chemistry in both the fullscale tests and the small-scale animal tests were comparable. Since, in general, the other tenability criteria are reached before significant oxygen depletion occurs, it is believed that the comparison can provide a useful estimate of the toxic potency of the gases in the compartment.

The tenability program (TENAB) also calculates the time exposure Ct, where $C$ is the mass concentration of decomposition products in the upper portion of the compartment, $\mathrm{g} / \mathrm{m}^{3}$, and $t$ is the exposure time, $s$. An estimated 30 minute $L C_{50}$ can be determined by dividing $C t$ by 30 . An $L C_{50}$ value represents the mass concentration necessary to $\mathrm{kill} 50 \%$ of those exposed. However, for this application, incapacitation is more meaningful than lethality. It has been suggested that values of $1 / 3$ to $1 / 2$ of the lethal values of $C t$ be used as an indicator of incapacitation.

Table 7 ists the estimated maximum $L_{5} C_{50}$ values for incapacitation for the fires of 300 seconds and 1000 seconds duration. The LC 50 values were calculated for heat of combustion values of $8 \mathrm{MJ} / \mathrm{kg}$ and of $21 \mathrm{MJ} / \mathrm{kg}$. The

\begin{tabular}{|c|c|c|c|c|c|}
\hline \multicolumn{5}{|c|}{ Table 7. Estimated LC of Combustion Gases that would Cause } \\
\hline Incapacitation
\end{tabular}

fires of particular interest are the smallest ones for which the TEMP1 Iimit indicated incapacitation. These are the $347 \mathrm{~kW}$ and $323 \mathrm{~kW}$ fires for 300 second and 1000 second duration fires, respectively. The calculated $L_{50}$ values for these two fires ranged from 1 to $7 \mathrm{~g} / \mathrm{m}^{3}$. Small-scale toxicity data [1] show that, except for melamine-treated polyurethane foam, all of the bus seat materials have much higher LC $_{50}$ values. Melamine-treated polyurethane foam has an $\mathrm{LC}_{50}$ of $10 \mathrm{~g} / \mathrm{m}^{3}$.

\section{SUMMARY AND CONCLUSIONS}

The fire assessment of materials suitable for use in the interiors of school buses needs to be judged on the basis of the materials' potential for causing the development of life-threatening conditions in the event of a deliberate or accidental fire. By combining computer fire model calculations with full-scale fire tests, limits were defined for the size (rate of heat release) of the ignition source, such that the development of hazardous conditions could be attributed to the fire performance of the seat assembly. 
HAZARD $I$ analysis whs used to determine the impact on tenability of different ignition sources in a large school bus enclosure. It was found that for the compartment size used in this study:

- incapacitating conditions developed between $250 \mathrm{~kW}$ and $500 \mathrm{~kW}$;

- lethal conditions developed at about $1000 \mathrm{~kW}$.

- Tenability analysis of HAZARD I tests of a model burning item with a known rate of heat release and gas yields showed that:

- a temperature criterion of $65^{\circ} \mathrm{C}$ is the most stringent of the tenability criteria;

- toxicity, for expected seating materials, would incapacitate people no sooner than would temperature.

Tenability analysis of the full-scale test data showed that:

- three seat assembiles produced incapacitating conditions $\left(F_{1} / C_{1}\right.$, $\mathrm{F}_{2} / \mathrm{C}_{3}$, and $\mathrm{F}_{3} / \mathrm{C}_{3}$ ) in the bus enclosure;

- one seat assembly $\left(F_{1} / C_{1}\right)$ produced lethal conditions in the bus enclosure;

- three seat assemblies did not produce an incapacitating or lethal environment in the bus enclosure.

\section{REFERENCES}

[1] Braun, E., Davis, S., Klote, J.日., Levin, B.C., and Paabo, M., Assessment of the Fire Performance of School Bus Interior Components, Natinonal Institute of Standards and Technology, NISTIR 90-4347 (1990).

Bukowsk1, R.W., Peacock, R.D., Jones, W.W., and Forney, C.L., Technical Reference Guide for the Hazard I Fire Hazerd Assessment Method; Nat. Inst, Stand, \& Tech, (U.S.), NIST Eandbook 146, Vol. II (1889).

American Soctety for Testing and Materials, 1983 Annual Book of ASTM Standards, "Proposed Method for Room Fire Test of Wall and Celling Matertals and Assemblies," E-5 Proposal, Section 4 , Vol. 04.07 , Phlladelphia, PA, p. 958 (1983).

[4] Litant, I., Guldelines for Flambility and Smoke Emission Specifications - TSC-76-LFS-6, Department of Transportation (July 1976).

[5] Peacock, R.D., Davis, S., and Lee, B.T., An Experimental Data Set for the Accuracy Assessment of Room Fire Models, Nat. Bur, Stand. (U.S.), NBSIR 88-3752 (1988).

[6] Babrauskas, V., Upholstered Furniture Room Fires - Measurements, Comparison with Furniture Calorimeter Data, and Flashover Predictions, J, Fire Sci, 2, S (1984).
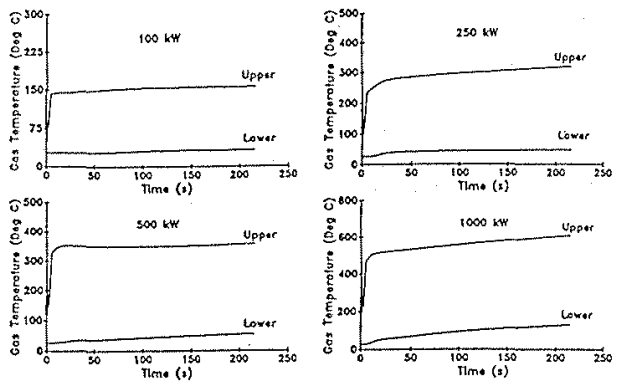

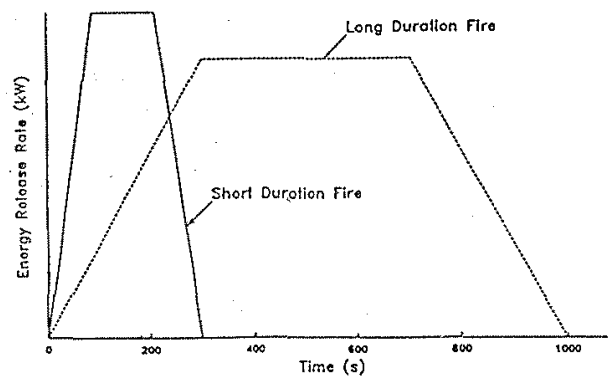

Figure 2. Representatke heat relesse curves for bus seats 